\title{
Qual mundo para a criança ${ }^{71}$
}

\section{Vera Regina J. R. M. Fonseca 72}

Farei uma cronologia: na década de 50, sendo eu uma criança, o mundo me parecia uma plataforma flutuante entre a ansiedade e o encanto. Ansiedade frente à separação dos meus pais e irmãos, ao eventual clima de tensão familiar, às demandas severas de alguns adultos (principalmente da escola). E encanto pela natureza, pelos brinquedos, por desenhar e pintar, recriando o mundo com uma aquarela barata, encanto pelos livros. Destes, os que mais me cativaram foram os de Monteiro Lobato, como muitos de minha geração. Eu procurava identificar nas paisagens do meu entorno a sombra dos bambuzais, do Capoeirão do Tucano Vermelho, o murmúrio do Riacho das Águas Claras, os troncos das jabuticabeiras...Mas, menina da cidade que era, só nas viagens de férias ao sul de Minas iria reconhecer a marca da natureza do meu país. Lá, na cidade minúscula do meu pai, encontrava a liberdade de brincar pelas ruas, ir sozinha comprar doces, andar de carro de boi, passear a pé na estrada.

Essas mesmas categorias de experiência, entre o medo e o encanto, são narradas no filme sueco "O Mundo Encantado de Åke", do diretor Allan Edwall (1984). Numa atmosfera de magia e névoa, é descrita a visão que Åke, um menino de 6 anos, tem do mundo: os pais são a base de sua confiança, e o pavor (aliado a certa curiosidade) é vivido frente a outros personagens: o diretor da escola, a prima louca, o zelador...

Ao me sentar para escrever o texto, vem mais uma lembrança insistente: em 1979, visitei a Suécia para encontrar parentes de lá. Fui visitar a escola que minha sobrinha, na época com 4 anos, frequentava. Marcou-me a arquitetura e organização do prédio, com pias baixas e pequenos fogões adaptados para as crianças. Lembro-me também da quase reverência com a qual as crianças eram tratadas na época, diferente do que eu via aqui. Não acho que a Suécia seja o paraíso, e hoje vejo o país com olhos mais críticos, mas o lugar que a criança tinha

\footnotetext{
${ }^{71}$ Trabalho apresentado na mesa “Criança: qual o mundo para ela?” no II Simpósio Bienal SBPSP “Fronteiras da Psicanálise: a clínica em movimento” no dia 22 de agosto de 2020.

${ }^{72}$ Analista didata da SBPSP, psiquiatra, pós-doutorado pelo IP-USP, diretora do Instituto Durval Marcondes da SBPSP, editorial board do International Journal.
} 
(e parece ainda ter) na sociedade sueca é marcante.

A insistência dessa lembrança me indica uma linha de associação: a adaptação da sociedade e do Estado às necessidades da criança é um elemento fundamental (ainda que não suficiente) para o desenvolvimento de um mínimo de segurança básica, a partir da qual diversos desenlaces podem ocorrer. E notem que não estou ainda nem considerando o papel da díade e da tríade. Acho que tudo começa com a sociedade e o Estado, porque é a sociedade, e seu braço executivo, o Estado, que irão garantir a proteção ao casal parental para que se dediquem à tarefa de criar uma criança. Utopia? Pode ser, mas nem por isto podemos deixar de lado esta questão crucial.

Aqueles que têm os meios poderão decidir como administrar a questão, individualmente e de acordo com sua disponibilidade pessoal, mas sabemos que há milhões de famílias que não têm muita escolha.

“... o total de famílias no Brasil é de aproximadamente 69 milhões. Desse número, 2,7\%, equivalentes a 1,8 milhão de famílias, têm um rendimento superior a $R \$ 23$ mil. Enquanto isso, 23,9\%, equivalentes a 16,4 milhões de famílias, recebem somente até $R \$ 1.908$, correspondentes a dois salários mínimos. São 12,8 milhões de famílias com rendimento mensal entre $R \$ 1.908$ e $R \$$ 2.862; 21,8 milhões de famílias com rendimento entre $R \$ 2.862$ e $R \$$ $5.724 " 73$.

Isto significa que a possibilidade de tais famílias se adaptarem à criança e suas necessidades esbarra na falta de recursos para tal. Poucos recursos frequentemente se associam a baixo apoio social, e este é um dos elementos mais influentes na prevalência da depressão pós-parto (DPP), sabidamente uma condição que impede a mãe de rastrear e atender as demandas do bebê. Em uma pesquisa da qual participei entre 2007 e 2009, comparando a prevalência de DPP em um hospital público e um privado, foi encontrada a taxa de $26 \%$ no público contra $9 \%$ no privado (Morais, Fonseca e col., 2015).

Apesar de ser óbvia tal relação, não se pode deixar de salientá-la, na esperança de que surjam esforços convergentes para lidar com o problema de apoio à díade e à tríade. Além do papel do estado, a presença dos avós, de parentes, a existência de um senso de comunidade, são elementos protetores que enriquecerão direta e indiretamente a vida da criança.

${ }_{73}$ https://educa.ibge.gov.br/jovens/matérias-especiais/20786-perfil-das-criancas-brasileiras.html 
Se algum grau de adaptação, necessariamente imperfeita, ocorre, a criança pode se mover para os próximos passos do processo que permitirá a elaboração do medo, da vulnerabilidade (que é marca da criança), e a organização dos movimentos defensivos para se haver com isso.

O eixo da minha apresentação é que a vulnerabilidade e o medo modulam a infância do homem e seu desenvolvimento, e é uma tarefa precípua dos pais e da sociedade criarem um ambiente em que o medo possa ser minimamente elaborado. Por outro lado, “...mesmo no desenvolvimento normal, a mãe (ou o pai, enfim, o adulto que cuida) não é só percebida como objeto atraente e a ser atraído, mas, simultaneamente, como inimigo em potencial, objeto de medo e talvez de ódio" (Fonseca, 2011).

Vou trazer uns poucos exemplos, tendo certeza de que cada um de vocês também teria vários.

Uma criança de 2 anos está na sala comigo; é sua segunda observação. A mãe, afirmando que ele fica muito bem sem ela, sai. O menino a acompanha com os olhos arregalados; enquanto isso, ofereço alguns brinquedos: um bebê, uma mamadeira, um ursinho...ele dá a mamadeira para este último, por muito tempo e rigidamente. De repente, percebo que um exantema (uma erupção cutânea de manchas vermelhas) começa a se formar, e vai subindo dos braços e pescoço para a cabeça. Seu medo frente à separação, que não podia ser detectado pela mãe, só se expressava na pele e na posição rígida, mas de modo dramático.

Um menino em análise comigo há vários anos e em alta frequência, quando começou a desenhar, cobria uma folha com rabiscos de caneta, até ficar tudo escuro, deixando apenas dois Olhos vermelhos visíveis: o jacaré do pântano. $\mathrm{O}$ mesmo desenho foi repetido centenas de vezes, à semelhança dos sonhos traumáticos.

Outro, em vários desenhos, expressa a condição de vulnerabilidade infantil de modo inquestionável, por exemplo, por meio de um monstro imenso que esmaga as crianças com seus pés, enquanto elas, em pânico, tentam fugir.

$\mathrm{Na}$ outra ponta do espectro, um adolescente, encaminhado pela escola por conta de comportamento frequente de bullying, só se interessa por armas e geopolítica da guerra; mostra uma enorme habilidade para guardar nomes estrangeiros e aprender novas línguas por si só. Ao conversar com o pai, que o paciente quase não vê, encontro uma pessoa com um grau raro de narcisismo 
explícito (raro porque as pessoas normalmente tendem a disfarçar tais traços no primeiro contato). O pai tinha uma imagem de si tão inflada que a possibilidade de servir como protetor e parceiro do filho desapareceram. Ele era só o competidor- o que resta ao menino é se impor aos outros como o grande bully e ser tanto grandioso como inflexível em sua belicosidade.

Como nos viramos, então, com o medo?

Se tivermos recursos de transformação simbólica, quando crianças, podemos virar heróis, vencendo o medo com a ajuda de uma fada ou um mago...numa espécie de negociação com o perigo e o medo, transformando a impotência em potência. Mas será necessário ter tido contato com a primeira...deixando que a impotência e o medo permaneçam um mínimo- devido à experiência de ter sido cuidado e/ou à tolerância pela emoção...

Um paciente de 11 anos, filho de pais separados e em litígio, dizia: "Eu só tenho sonhos que eu próprio faço e resolvo como eles vão acontecer”, uma afirmação triunfante que o adolescente guerreiro também fazia. Se descartamos o medo antes de ele ser reconhecido, teremos uma construção maníaca tendendo à hipérbole, em que só se ganha, só se destrói. Essa é uma via aditiva e esterilizante, que transforma o mundo em um lugar no qual as fadas não são mais necessárias, os monstros se destroem só de terem pensado em existir, em que a realidade não é testada, mas negada, em que só a truculência tem lugar - será que reconhecemos tais traços no momento atual?

Mas é exatamente a fragilidade da infância que nos mobiliza, nos emocionaporque de alguma forma a guardamos para sempre invicta dentro de nós. Para quem a expulsou, resta a noite eterna dos cassinos de Las Vegas, em que há apenas o metralhar de estímulos excitantes e repetidos.

E é esta negação que está presente na história dos adultos em torno das crianças abusadas- elas são abusadas neste mesmo mundo, onde a fragilidade periga entrar na mente do adulto, e é expulsa imediatamente através da ação violenta sobre o elemento mais frágil.

Por fim, trago uma outra pergunta: E as crianças que, apesar de não desenvolverem patologia incapacitante, se normalizam, se adaptam, mas nunca têm a experiência de que podem ser agentes de mudança de sua própria vida e do mundo? Que carregam como opção apenas soluções individuais, tipo apagar ou fugir, e nunca cogitam em soluções coletivas, pois não têm esperança no dual e, 
portanto, no grupal? O que será que faz com que algumas crianças, e os adultos que elas se tornam, não pensem em lutar, em protestar?

Uma paciente espera de Deus a solução: tem fé que ele virá sempre que precisar... quando bebê, seus pais biológicos mais a machucaram que nutriram depois foi adotada por alguém que ameaçava devolvê-la se ela se comportasse mal. Acabou, muito jovem, se juntando a um homem que a sustentava, desde que pudesse se impor e abusar dela física e psicologicamente, usando-a como uma espécie de lata de lixo.

Outro paciente foi criado dentro da ideia de um Deus cruel e vingativo, que nunca seria sensível a suas necessidades. Assim eram seus pais, muito frios e religiosos. Portanto, a ideia de que é possível reclamar, é possível se juntar para conseguir algo, nunca lhe foi apresentada ou revelada!

Será este o cruzamento da ontologia (como cada um se desenvolve e em que ambiente) com a política (como cada um se vê como um cidadão e agente, ainda que dependa do grupo)? Num momento como este que vivemos, quantas pessoas têm a experiência de que a união pode trazer força?

Termino contando como seria, na minha visão, um bom mundo para as crianças. Elas viveriam apoiadas por uma rede social ampla, com pais, tios, avós, parentes e amigos. Teriam um lugar seguro para brincar com seus companheiros livremente; praças e bambuzais e muitas árvores. Teriam animais por perto e ouviriam histórias. Não precisariam se preocupar com alimentação, que estaria à sua disposição na medida justa. Na escola, seriam apresentadas às artes, à ciência e à magia do conhecimento. Teriam livros que pudessem encantá-las. Aprenderiam que é possível protestar, que é possível, com todas as dificuldades, viver e agir em grupo.

Teriam um senso de confiança de que há instâncias que as protegem, assim como suas famílias: a sociedade e o Estado.

\section{REFERÊNCIAS}

Fonseca, V. R. J. R. M. (2011). Medo e agressividade: entre a perspectiva da psicanálise e da etologia. Trieb, v. 10, n. 1/2, 193-215.

Morais, Maria de Lima Salum e, Fonseca, Luiz Augusto Marcondes, David, Vinicius Frayze, Viegas, Lia Matos, \& Otta, Emma. (2015). Fatores psicossociais e sociodemográficos associados à depressão pós-parto: Um estudo em hospitais 
público e privado da cidade de São Paulo, Brasil. Estudos de Psicologia (Natal), 2O(1), 40-49. 